\title{
EFFICACY OF KETOCONAZOLE IN HORMONE REFRACTORY PROSTATE CANCER PATIENTS
}

\author{
PARVEEN SHAHIDA AKHTAR ${ }^{1}$, RIAZ AHMED CHOWDHURY², JAFAR MD. MASUD ${ }^{3}$
}

\begin{abstract}
:
Prostate cancer is a common malignancy among males, with the incidence steadily rising over the past years. Patients with small volume metastasis where early chemotherapy is not warranted, in patients with biochemical failure, and in patients who refuse chemotherapy, management remains controversial as there is no universally accepted treatment protocol. Ketoconazole is an antimycotic that inhibits cytochrome P450 enzymes that are required for the synthesis of androgens and other steroids. In addition, in-vitro studies have suggested some direct cytotoxic effects in prostate cancer cell lines. This study aims to describe our experience with ketoconazole treatment for hormone refractory prostate cancer (HRPC) at our centre. Retrospective chart review of HRPC patients given ketoconazole at a private oncology centre in Dhaka from 2005 - 2006 was done. Patients had histologically proven adenocarcinoma of the prostate with rising Prostate Specific Antigen (PSA) despite androgen deprivation therapy (ADT) with orchiectomy, LHRH agonist therapy and antiandrogens. Ketoconazole was given at $200 \mathrm{mg}$ thrice daily. A total of 10 patients with HRPC was treated and evaluated for response and toxicity. Median age was 70 years old.4 (40\%) of the 10 patients had a greater than 50\% decrease of PSA values. Responses were seen in $66.66 \%(2 / 3)$ of patients with bone-only disease, $20 \%(1 / 5)$ of patients with bone and soft tissue disease and 1 patient with PSA-only disease. Median duration of response was 6.75 months (range 2-14 months).There were no grade 3 or 4 toxicities. Overall, $5(50 \%)$ patients had toxicity related to ketoconazole. Its good toxicity profile, low cost and ease of administration makes it a viable option to this group of patients specially in our country.
\end{abstract}

Keyword: Prostate cancer, hormone refractory prostate cancer, ketoconazole

\section{Introduction}

Prostate cancer is a common malignancy among males, with the incidence steadily rising over the past years. ${ }^{1}$ With the advent of Prostate Specific Antigen (PSA), the incidence of prostate cancer is not on the rise, disease recurrence is also detected earlier. PSA detects a subset of patients with biochemical failure, defined as a rising PSA without objective evidence of metastasis after treatment for localized disease. Although some of these patients may be treated conservatively, there are patients treated early with androgen deprivation therapy (ADT) either due to the poor prognostic factors or due to patients' or even physicians' psychological refusal to accept conservative approach. Despite high response rate of $80-90 \%$ with $\mathrm{ADT}$ these patients will eventually become hormone resistant, with a progression-free duration of 18 to 24 months. Docetaxel-based chemotherapy is effective in hormone refractory prostate cancer with a survival advantage when used as first line treatment and is now the standard of care in metastatic hormone refractory prostate cancer (HRPC). ${ }^{2}$ However, in patients with small volume metastasis where early chemotherapy is not warranted, in patients with biochemical failure, and in patients who refuse chemotherapy, management remains controversial as there is no universally accepted treatment protocol. Therefore, there is a void in the management of these patients.

Ketoconazole is an antimycotic that inhibits cytochrome P450 enzymes which are required for the synthesis of androgens and other steroids. In addition, in-vitro studies have suggested some direct cytotoxic effects in prostate cancer cell lines. ${ }^{3,4}$ Studies of ketoconazole done during the pre-PSA era have shown response rates of $11-13 \%$ and disease stabilization in

1. Professor \& Head, Department of Medical Oncology, NICRH, Mohakhali, Dhaka

2. Associate Professor, Department of Surgery, Bangladesh Medical College, Dhaka

3. Assistant Professor, Department Oncology, Bangladesh Medical College, Dhaka

Correspondence : Prof. Parveen Shahida Akhtar, Professor \& Head, Department of Medical Oncology, NICRH, Mohakhali, Dhaka 
37-50\% accompanied by marked palliation of pain. ${ }^{5,6}$ Present studies using PSA as a marker of response showed a greater than $50 \%$ decrease in PSA in 40 $63 \%$ of HRPC patients given high dose ketoconazole (HDK) at $400 \mathrm{mg}$ thrice daily. ${ }^{7-9}$ Median duration of response was 6 months. ${ }^{8}-10$ A phase III trial using HDK with anti-androgen withdrawal (AAWD) vs AAWD alone reported PSA responses of $27 \%$ and $11 \%$, respectively, with time to PSA progression 8.6 months in responders. ${ }^{11}$ However, there were some grade 3 4 toxicities noted with all these studies including neurotoxicity, lassitude and hepatic toxicity. One approach to reduce toxicity is to use lower doses of ketoconazole. A phase II trial by Harris et al using low dose ketoconazole (LDK) at $200 \mathrm{mg}$ thrice daily showed a response rate of $46 \%$ with fewer side effects while another trial had a 55\% response rate with ketoconazole at $300 \mathrm{mg}$ thrice daily. ${ }^{12,13}$ This study aims to describe our experience with ketoconazole treatment for HRPC at our centre.

\section{Materials \& Methods}

Retrospective chart review of HRPC patients given ketoconazole at a private oncology centre in Dhaka from 2005 - 2006 was done. Patients had histologically proven adenocarcinoma of the prostate with rising PSA despite ADT with orchiectomy, LHRH agonist therapy and anti-androgens.

Ketoconazole was given at $200 \mathrm{mg}$ thrice daily. Replacement doses of oral hydrocortisone or prednisolone were given in four out of 10 evaluable patients. Patients had monthly follow-up visits to evaluate for toxicities or adverse events. Complete blood counts, liver function tests and PSA were done monthly. Response was defined as a PSA decline of at least $50 \%$ from pre-treatment level and confirmed by a second PSA value four or more weeks later. Endpoints were to determine response and duration of response. Secondary endpoint was to determine toxicity profile.

\section{Results}

A total of 10 patients with HRPC was treated and evaluable for response and toxicity. Median age was 70 years (range 57-85 years). Three had bone-only disease, five had bone and soft tissue disease, one had soft tissue-only disease and one had PSA-only disease. Median PSA was $354.5 \mathrm{ig} / \mathrm{ml}$ (range 22.4-2500 ig/ml) at the start of ketoconazole (Table-I).

Four (40\%) of the 10 patients had a greater than $50 \%$ decrease of PSA values with ketoconazole. Responses were seen in $66.66 \%(2 / 3)$ of patients with bone-only disease, $20 \%(1 / 5)$ of patients with bone and soft tissue disease and one patient with PSA-only disease. Median duration of response was 6.75 months (range 2-14 months). Median time to reach PSA nadir was 5.06 months (range 1.5-11 months) (Tabel-II). Two patients continue to exhibit response at the time of writing. Out of the 4 responders, ketoconazole was increased to $400 \mathrm{mg}$ in one patient due to subsequent rise in PSA values after initial response and responded to ketoconazole $400 \mathrm{mg}$.

Ketoconazole was generally well-tolerated. There were no grade 3 or 4 toxicities. Overall, $5(50 \%)$ patients had toxicity related to ketoconazole. 4 patients had grade 1 elevations in transaminases.

Table-I

Pretreatment Characteristics $(n=10)$

\begin{tabular}{|c|c|}
\hline \multicolumn{2}{|l|}{$\overline{\text { Age }}$} \\
\hline Median & 70 years \\
\hline Range & $57-85$ years \\
\hline \multicolumn{2}{|l|}{ Extent of disease } \\
\hline Bone only & 3 \\
\hline Bone and soft tissue & 5 \\
\hline Soft tissue only & 1 \\
\hline PSA only & 1 \\
\hline \multicolumn{2}{|l|}{ PSA at entry } \\
\hline median & $354.5 \mathrm{ug} / \mathrm{ml}$ \\
\hline Range & $22.4-2500 \mathrm{ug} / \mathrm{ml}$ \\
\hline \multicolumn{2}{|c|}{$\begin{array}{c}\text { Table-II } \\
\text { Clinical outcomes on responders }(n=10)\end{array}$} \\
\hline$\overline{\text { PSA }>50 \% \text { decline }}$ & $4(40 \%)$ \\
\hline Bone only & 2 \\
\hline Bone and soft tissue & 1 \\
\hline PSA only & 1 \\
\hline \multicolumn{2}{|l|}{ Time to PSA nadir } \\
\hline Median & 5.06 months \\
\hline Range & 1.5-11 months \\
\hline \multicolumn{2}{|l|}{ Duration of response } \\
\hline Median & 6.75 months \\
\hline Range & 2-14 months \\
\hline \multicolumn{2}{|l|}{ Adverse events } \\
\hline Grade 1 transaminitis & 4 \\
\hline Grade 2 transaminitis & 1 \\
\hline
\end{tabular}




\section{Discussion}

A $40 \%$ PSA response was noted in this retrospective study of low dose ketoconazole in HRPC patients. This result is almost similar to that of Harris et al where a $46 \%$ PSA response was demonstrated. ${ }^{12}$ Ketoconazole should be taken on an empty stomach as drug absorption is better with an acidic gastric environment. If possible, antacids, $\mathrm{H}_{2}$ blockers or proton pump inhibitors should not be taken. These measures may not have been followed by patients resulting in suboptimal bioavailability of the drug.

The use of PSA as an endpoint is still a subject of debate at present. However, PSA has been welldocumented as a surrogate marker of response. Changes in PSA may antedate changes in bone scans which may have a significant bearing in management. ${ }^{14}$ A PSA response has also been correlated with improved median survival and time to treatment failure. ${ }^{11,14-16}$

Replacement doses of hydrocortisone or prednisolone were given to patients as ketoconazole is a potent inhibitor of adrenal steroid synthesis. Corticosteroids in itself exhibit anti-tumor effects by ACTH inhibition via negative feedback. This results to decreased androgen production in the adrenals. Hydrocortisone and prednisone have shown $16-22 \%$ PSA response while one study using dexamethasone has shown $61 \%$ PSA response. ${ }^{17}$ There are no randomized trials to say which of the above steroids is most effective. In our study, steroids were given only in $50 \%$ of patients, hence, its use may have an additive effect on ketoconazole but our result of $40 \%$ PSA response demonstrates that ketoconazole accounts for most of the activity.

Toxicities were minimal in our study. Although 50\% reported adverse effects, they were generally manageable and no one discontinued the drug. This is in contrast with the studies on high dose ketoconazole. where grade 3-4 toxicities were noted necessitating discontinuation of the drug. $9,10,18$ No symptoms of adrenal insufficiency were seen in the patients who were not given steroids. This suggests that steroids may be omitted in patients with low dose ketoconazole but this should be further explored in a randomized clinical trial where steroid function is monitored.Limitations of this study include limited number of patients evaluated and that quality of life was not assessed.

\section{Conclusion}

Low dose ketoconazole bridges the gap in the continuum of treatment for patients with biochemical failure who have failed ADT and in HRPC with small volume metastasis where cytotoxic chemotherapy would have a significant impact on quality of life. Its good toxicity profile, low cost and ease of administration makes it a viable option to this group of patients specially in our country. Further studies are needed to explore this aspect of HRPC. We await the result of a study by the Eastern Cooperative Oncology Group (ECOG). ECOG 1899 is a phase III randomized trial evaluating second line hormonal therapy (ketoconazole/hydrocortisone) versus combination chemotherapy (docetaxel/estramustine) on progression free survival in HRPC patients. ${ }^{19}$

\section{References}

1. Seow A, Koh WP, Chia KS, et al. Trends in Cancer Incidence in Singapore 1968- 2002.

2. Tannock IF, de Witt R, Berry WR, et al. Docetaxel plus prednisone or mitoxantrone plus prednisone for advanced prostate cancer. NEJM 2004; 351: 1502-1512.

3. Petrylak DP, Tangen CM, Hussain MHA et al: Docetaxel and estramustine compared with mitoxantrone and prednisone for advanced refractory prostate cancer. NEJM 2004; 351: 15131520

4. Rochlitz CF, Damon LE, Russi MB, et al. Cytotoxicity of ketoconazole in malignant cells. Cancer Chemother Pharmacol 1988; 21: 319-322.

5. Eichenbeger T, Trachtenberg J, Toor P et al. Ketoconazole: a possible direct cytotoxic effect of prostate carcinoma cells. J Urol 1989;141:190.

6. Johnson DE, Babaian RJ, von Eschenbach AC et al: Ketoconazole therapy for hormonally refractive metastatic prostate cancer. Urology 1988; 31:132134.

7. Trump DL, Havlin KH, Messing EM, et al. High dose ketoconazole in advanced hormone refractory prostate cancer: endocinologic and clinical effects. J Clin Oncol 1989; 7: 1093-1098.

8. Oh W: Secondary hormonal therapies in the treatment of prostate cancer. Urology 2002; 60 (Suppl 3A):87-93.

9. $\quad$ Figg WD, Liu Y, Arlen P, et al: A randomized phase II trial of ketoconazole plus alendronate versus ketoconazole alone in patients with androgen independent prostate cancer and bone metastases. J Urol 2005;173:790-796. 
10. Scholtz M, Jennrich R, Strum S, et al: Long-term outcome for men with androgen independent prostate cancer treated with detoconazole and hydrocortisone. J Urol 2005;173:1947-1952.

11. Small EJ, Halabi S, Dawson NA, et al: Antiandrogen withdrawal alone or in combination with ketoconazole in androgen-independent prostate cancer patients: a phase III trial (CALGB 9583). J Clin Oncol 22:1025-1033.

12. Harris KA, Weinberg V, Bok RA, et al. Low dose ketoconazole with replacement doses of hydrocortisone in patients with progressive androgen independent prostate cancer. J Urol 2002;168:542545 .

13. Wilkinson S, Chodak G. An evaluation of intemediate-dose ketoconazole in hormone refractory prostate cancer. Eur Urol 2004;45:581584.

14. Bubley GJ, Carducci M, Dahut W et al: Eligibility and response guideline for phase II clinical trials in androgen-independent prostate cancer: recommendations from the prostate-specific antigen working group. J Clin Oncol 1999; 17:3461-3467.
15. Ritchie JP: Anti-androgens and other hormonal therapies for prostate cancer. Urol 1999; 54(suppl $6 \mathrm{~A}): 15-18$.

16. Kelly WK, Scher HI, Mazumdar M et al: Prostate specific antigen as a measure of disease outcome in metastatic hormone refractory prostate cancer. J Clin Oncol 1993;11(4):607-615

17. Ryan CJ, Small EJ: Role of secondary hormonal therapy in the management of recurrent prostate cancer. Urol 2003;62(suppl 6B):87-94

18. Millikan R, Baez L, Banerjee T et al: Randomized phase II trial of ketoconazole and ketoconazole/ doxorubicin in androgen independent prostate cancer. Urol Oncol 2001 (6):111-115

19. Walczak JR, Carducci MA: Phase 3 randomized trial evaluating second-line hormonal therapy versus docetaxel-estramustine combination chemotherapy on progression-free survival in asymptomatic patients with a rising prostate specific antigen level after hormonal therapy for prostate cancer: an Eastern Cooperative Oncology Group (E1899), intergroup/clinical trials support unit study. Urol 62(suppl 6B):141-146, 2003. 